\title{
ESTIMASI NILAI HERITABILITAS BERAT LAHIR, SAPIH, DAN UMUR SATU TAHUN PADA SAPI BALI DI BALAI PEMBIBITAN TERNAK UNGGUL SAPI BALI
}

\section{THE HERITABILITY ESTIMATION FOR BIRTH WEIGHT, WEANING WEIGHT AND YEARLING WEIGHT OF BALI CATTLE AT BALAI PEMBIBITAN TERNAK UNGGUL SAPI BALI}

\author{
Kaswati, Sumadi*, dan Nono Ngadiyono \\ Fakultas Peternakan, Universitas Gadjah Mada, Jl. Fauna No. 3, Bulaksumur, Yogyakarta, 55281
}

\section{INTISARI}

Penelitian ini bertujuan untuk mengestimasi nilai heritabilitas $\left(\mathrm{h}^{2}\right)$ berat lahir, sapih, dan umur satu tahun sapi Bali di Balai Pembibitan Ternak Unggul (BPTU) Sapi Bali. Materi penelitian yang digunakan yaitu catatan berat lahir, sapih dan berat umur satu tahun (365 hari) sapi Bali mulai tahun 2006 sampai 2009. Catatan silsilah berasal dari 150 ekor pedet sapi Bali yang berasal dari 9 ekor pejantan dengan 150 ekor induk sapi Bali. Estimasi nilai heritabilitas dilakukan berdasarkan analisis saudara tiri sebapak. Hasil penelitian menunjukkan bahwa heritabillitas berat lahir, sapih, dan satu tahun berturut-turut adalah $0,85 \pm 0,44 ; 0,51 \pm 0,32$, dan 0,54 $\pm 0,32$. Berdasarkan hasil tersebut dapat disimpulkan bahwa nilai heritabilitas berat lahir, sapih, dan umur satu tahun sapi Bali di BPTU Sapi Bali bernilai tinggi.

(Kata kunci: Heritabilitas, Berat lahir, Berat sapih, Berat satu tahun, Sapi Bali)

\section{ABSTRACT}

The study was conducted to estimate heritability $\left(h^{2}\right)$ of birth weight, weaning weight and yearling weight of Bali Cattle at Balai Pembibitan Ternak Unggul (BPTU) Sapi Bali. This study used pedegree record including birth weight, weaning weight and yearling weight (365 days) from 2006 to 2009 years. The recording of pedigree were collected from 150 Bali calves which inherited from the crossing between 9 bulls and 150 dams. The estimation of heritability were analysed by Paternal Halfsib Correlation method. The results indicated the heritability of birth weight, weaning weight and yearling weight were $0.85 \pm 0.44 ; 0.51 \pm 0.32$ and $0.54 \pm 0.32$ respectively. Inconclusion, heritability of birth weight, weaning weight and yearling weight of Bali Cattle at BPTU Sapi Bali remain in high level.

(Key words: Bali cattle, Birth weight, Heritability, Weaning weight, Yearling weight)

\section{Pendahuluan}

Sapi Bali merupakan ternak asli Indonesia yang mempunyai masa depan ekonomis cerah $(a$ promising economic future) dan telah tersebar di 26 propinsi di Indonesia. Penyebaran sapi Bali cukup luas terutama di propinsi Sulawesi Selatan, NTT, NTB, Lampung, Sulawesi Tengah, Kalimantan Selatan, Kalimantan Barat, dan Jawa Timur. Penampilan sapi Bali pada daerah tersebut beragam, baik ukuran tubuh, pertumbuhan, maupun kemampuan reproduksi. Keragaman tersebut disebabkan oleh sistem pemeliharaan, perbedaan pakan dan lingkungan. Sapi Bali berpotensi dikembangkan di luar habitat asal karena sapi Bali memiliki penampilan menarik, kesuburannya tinggi, dan daya adaptasinya cukup baik terhadap lingkungan baru (Gunawan et al., 1998).

Seleksi terarah merupakan salah satu cara untuk meningkatkan produktivitas ternak disamping manajemen pemeliharaan. Beberapa hal seperti sifat

\footnotetext{
* Korespondensi (corresponding author):

Telp. +62 81328832260

E-mail: profsumadi@yahoo.co.id
}

individu, silsilah dan kemampuan reproduksi perlu diperhatikan dalam seleksi terarah. Hasil seleksi berupa sifat kuantitatif dan sifat kualitatif yang membentuk penampilan individu ternak dikendalikan oleh faktor genetik dan faktor lingkungan. Sifat kuantitatif dan kualitatif dapat diwariskan kepada anak keturunannya. Untuk menghitung besarnya proporsi dari keragaman suatu sifat yang diwariskan kepada anak keturunannya maka perlu dihitung angka pewarisan atau heritabilitas $\left(\mathrm{h}^{2}\right)$. Jika angka pewarisan pada suatu sifat tinggi maka diharapkan keunggulan suatu sifat tetua yang diwariskan kepada keturunannya juga tinggi.

Suatu sifat dipilih untuk dijadikan dasar seleksi perlu dipertimbangkan beberapa hal, yaitu tujuan program seleksi, nilai heritabilitas suatu sifat, nilai ekonomi dari adanya peningkatan sifat, korelasi antar sifat serta biaya dan waktu dari program seleksi. Beberapa sifat yang mempunyai nilai ekonomis tinggi meliputi fertilitas, daya hidup, nilai karkas, berat lahir, berat sapih, tipe dan konformasi tubuh, berat dan kualitas bulu (Warwick et al., 1990). Berdasarkan uraian tersebut di atas, maka dilakukan penelitian tentang estimasi nilai 
heritabilitas berat lahir, sapih, dan umur satu tahun pada sapi Bali di BPTU Sapi Bali, Jembrana, Bali.

Tujuan penelitian ini adalah untuk mengetahui nilai heritabilitas $\left(\mathrm{h}^{2}\right)$ berat lahir, sapih, dan umur satu tahun pada sapi Bali di BPTU Sapi Bali. Hasil penelitian ini diharapkan dapat mengetahui besarnya proporsi genetik yang diwariskan serta dapat menjadi pedoman dalam pelaksanaan seleksi calon pejantan dan induk untuk dijadikan bibit.

\section{Materi dan Metode}

Penelitian ini dilaksanakan pada bulan Maret sampai April 2011 di Balai Pembibitan Ternak Unggul (BPTU) Sapi Bali, Jembrana, Bali. Materi yang digunakan dalam penelitian ini adalah data silsilah dari 150 ekor pedet sapi Bali yang berasal dari 9 ekor pejantan dengan 150 ekor induk sapi Bali.

\section{Pengambilan data}

Penelitian ini dilakukan dengan menggunakan catatan data yang meliputi berat lahir, berat sapih (umur 205 hari), dan berat umur satu tahun (umur 365 hari) dari tahun 2006 sampai 2009 yang terdapat di Balai Pembibitan Ternak Unggul (BPTU) Sapi Bali.

Data silsilah yang berhasil dikumpulkan berasal dari 150 ekor induk dengan 9 ekor pejantan. Setiap pejantan mengawini beberapa ekor induk yang tidak sama jumlahnya dan menghasilkan 150 ekor pedet yang digunakan untuk estimasi nilai heritabilitas.

\section{Analisis data}

Data silsilah yang berhasil dikumpulkan dari keturunan tiap pejantan yang mengawini beberapa ekor induk meliputi: berat lahir, berat sapih, dan berat umur satu tahun.

Berat lahir, sapih, dan umur satu tahun dikoreksi terhadap jenis kelamin dan umur induk (Hardjosubroto, 1994). Rumus yang digunakan untuk penyesuaian yaitu sebagai berikut:

$\mathrm{BL}_{\text {terkoreksi }}=\mathrm{BL} \times \mathrm{FKUI} \times \mathrm{FKJK}$
$\mathrm{BS}_{\text {terkoreksi }}=\left(\frac{\mathrm{BB}-\mathrm{BL}}{\text { umur }} \times 205+\mathrm{BL}\right)(\mathrm{FKUI})(\mathrm{FKJK})$

$\mathrm{BST}_{\text {terkoreksi }}=\left(\frac{\mathrm{BB}-\mathrm{BS}}{\text { tenggang waktu }} \times 160+\mathrm{BS}_{205}\right)(\mathrm{FKUI})(\mathrm{FKJK})$

Keterangan:

$\mathrm{BL}_{\text {terkoreksi }}=$ berat lahir terkoreksi

$\mathrm{BS}_{\text {terkoreksi }}=$ berat sapih terkoreksi

$\mathrm{BST}_{\text {terkoreksi }}=$ berat satu tahun terkoreksi

FKUI $\quad=$ faktor koreksi umur induk

FKJK $\quad=$ faktor koreksi jenis kelamin

Pendugaan angka pewarisan atau heritabilitas dilakukan dengan analisis variansi menggunakan data saudara tiri sebapak (Paternal Halfsib Correlation). Pemisahan komponen ragam untuk menduga nilai heritabilitas dilakukan dengan analisis sidik ragam Rancangan Acak Lengkap pola searah (Completely Randomized Design One - Way Classification), dengan model matematik sebagai berikut (Becker, 1992 dan Hardjosubroto, 1994):

$$
\mathrm{Y}_{\mathrm{ik}}=\mu+\alpha_{\mathrm{i}}+\mathrm{e}_{\mathrm{ik}}
$$

Keterangan:

$Y_{\mathrm{ik}}=$ pengamatan pada individu ke-k pada pejantan ke-i

$\mu=$ rata - rata populasi

$\alpha_{\mathrm{i}}=$ efek pejantan $\mathrm{ke}-\mathrm{i}$

$\mathrm{e}_{\mathrm{ik}}=$ eksperimental error

\section{Hasil dan Pembahasan}

\section{Berat lahir, sapih, dan umur satu tahun}

Rerata berat lahir (BL), berat sapih (BS) dan berat umur satu tahun (BST) sapi Bali di BPTU Sapi Bali tersaji pada Tabel 1. Variasi berat lahir ini diduga karena adanya variasi umur induk dan faktor lingkungan. Berat lahir pedet cenderung meningkat sampai kelahiran ke 4 dan ke 5 setelah itu akan menurun (Lasley, 1978 dan Hardjosubroto, 1994). Di samping itu pengaruh lingkungan seperti kesehatan sapi dan supply dalam pakan sangat penting karena mengakibatkan efek langsung pada performan sapi, misalnya melalui makanan, akibat penyakit, dan pengelolaan (Taylor, 1984; Pane, 1990).

Tabel 1. Rerata dan simpangan baku berat lahir, sapih, dan umur satu tahun sapi Bali di BPTU Sapi Bali (mean and standard deviaton of birth weight, weaning weight and yearling weight of Bali cattle at BPTU Sapi Bali)

\begin{tabular}{lc}
\hline \hline \multicolumn{1}{c}{ Sifat (trait) } & Rerata \pm simpangan baku (mean \pm standard deviation) \\
\hline Berat lahir (birth weight) & $17,8 \pm 1,08 \mathrm{~kg}$ \\
Berat sapih (weaning weight) & $88,59 \pm 16,15 \mathrm{~kg}$ \\
Berat umur satu tahun (yearling weight) & $131,12 \pm 25,50 \mathrm{~kg}$ \\
\hline
\end{tabular}


Rata-rata berat sapih sapi Bali pada penelitian ini lebih rendah dari hasil penelitian Sudrana (1988) yaitu 91,16 $\pm 5,40$ dengan rataan umur sapih 201,9 hari. Perbedaan rata-rata berat sapih disebabkan karena adanya variasi berat lahir dan umur sapih. Menurut Lasley (1978) berat sapih berkorelasi positif dengan berat lahir. Pedet yang mempunyai berat lahir tinggi akan tumbuh lebih cepat sehingga mencapai berat sapih yang tinggi. Umur pedet yang disapih lebih awal akan memiliki persentase berat sapih yang lebih rendah dibanding pedet yang disapih pada umur siap sapih. Hal ini karena sapi yang umurnya masih terlalu muda konsumsi pakannya masih rendah dan nutrisi yang dikonsumsi masih belum cukup (Taylor, 1984).

Rata-rata berat umur satu tahun sapi Bali pada penelitian ini lebih rendah dari hasil penelitian Jan (2000) yaitu $144,78 \pm 11,38 \mathrm{~kg}$. Perbedaan ratarata berat satu tahun diduga karena adanya faktor pejantan, dan faktor lingkungan. Pengaruh pejantan lebih penting pada semua perbedaan bangsa sebab akan menunjukkan perbedaan genetik untuk tumbuh dan bukan disebabkan oleh produksi susu (Warwick et al., 1990).

\section{Heritabilitas berat lahir, berat sapih, dan berat umur satu tahun}

Hasil estimasi nilai heritabilitas berat lahir, sapih dan satu tahun tersaji pada Tabel 2. Estimasi nilai heritabilitas berat lahir hasil penelitian ini lebih tinggi daripada yang dilaporkan Gunawan dan Jakaria (2011) pada bangsa sapi yang sama yaitu $0,09 \pm 0,07$ maupun pada sapi potong yang dinyatakan oleh Warwick et al. (1990) yaitu 0,35 sampai 0,45 dan Hardjosubroto (1994) yaitu 0,20 sampai 0,58 . Nilai heritabilitas hasil penelitian ini termasuk dalam kelas tinggi sesuai dengan pernyataan Dalton (1980) bahwa nilai heritabilitas termasuk dalam kelas tinggi apabila nilainya lebih tinggi daripada 0,3 (Dalton, 1980).

Salah baku heritabilitas berat lahir yang diperoleh lebih rendah daripada nilai heritabilitas yang berarti cukup andal bila digunakan dalam perhitungan rumus-rumus pemuliaan. Salah baku heritabilitas berat lahir pada penelitian ini masih relatif tinggi karena tingginya keragaman lingkungan dan jumlah data anak per pejantan yang bervariasi. Nilai heritabilitas tergantung dari keragaman lingkungan, metode analisis dan jumlah sampel yang digunakan (Warwick et al., 1990) dan heritabilitas berubah menurut jenis ternak, sifat, populasi, bangsa, waktu, dan daerah (Edey, 1983). Beberapa lingkungan dapat menyebabkan ekspresi perbedaan genetik yang lebih besar dan karena itu memperbesar keragaman genetik dan heritabilitas (Warwick et al., 1990). Waktu perhitungan dan populasi yang berbeda, akan menyebabkan perbedaan nilai heritabilitas yang diperoleh karena terjadi perubahan komposisi ternak dan ragam genetik yang terdapat di dalam populasi. Manajemen pengelolaan juga mempengaruhi nilai heritabilitas. Prosedur pengelolaan dibakukan semaksimum mungkin dan membuat penyesuaian terhadap pengelolaan atau lingkungan yang tidak memungkinkan akan meningkatkan nilai heritabilitas (Warwick et al., 1990).

Hasil estimasi nilai heritabilitas berat sapih lebih tinggi dibandingkan dengan hasil penelitian Sukmasari (2001) yaitu $0,23 \pm 0,02$, maupun Gunawan dan Jakaria (2011) yaitu 0,33 $\pm 0,09$. Namun demikian, estimasi heritabilitas pada penelitian ini berada pada kisaran 0,30 sampai 0,55 dan estimasi ini masuk kategori tinggi (Hardjosubroto, 1994). Nilai heritabilitas berat sapih yang tinggi menunjukkan tingginya keragaman yang diakibatkan pengaruh genetik aditif terhadap suatu sifat sedangkan selebihnya diakibatkan pengaruh genetik non aditif.

Nilai heritabilitas hasil penelitian menunjukkan bahwa berat sapih sapi Bali di BPTU Sapi Bali dapat ditingkatkan melalui seleksi individu. Heritabilitas suatu sifat yang termasuk dalam kelas tinggi menunjukkan tingginya korelasi antara genetik dengan performans yang terukur dan terlihat dari luar sehingga seleksi individu cukup efektif dilakukan pada populasi tersebut (Warwick et al., 1990). Selanjutnya, seleksi untuk meningkatkan berat sapih sekaligus dapat meningkatkan berat setahunan karena berat sapih berkorelasi genetik dengan berat setahunan pada derajat positif dan tinggi yaitu 0,72 $\pm 0,03$ (Sukmasari, 2001).

Salah baku berat sapih yang diperoleh lebih rendah dari nilai heritabilitasnya. Hal ini menunjukkan tingginya keterandalan nilai heritabilitas tersebut. Nilai heritabilitas tergantung dari keragaman lingkungan, metode analisis dan jumlah

Tabel 2. Estimasi nilai heritabillitas berat lahir, sapih dan umur satu tahun sapi Bali (estimation of heritability of birth weight, weaning weight and yearling weight Bali cattle)

\begin{tabular}{lc}
\hline \hline \multicolumn{1}{c}{ Sifat (trait) } & Heritabilitas \pm kesalahan baku (heritability \pm standard error) \\
\hline Berat lahir (birth weight) & $0,85 \pm 0,44$ \\
Berat sapih (weaning weight) & $0,51 \pm 0,32$ \\
Berat umur satu tahun (yearling weight) & $0,54 \pm 0,32$ \\
\hline
\end{tabular}


sampel yang digunakan (Warwick et al., 1990; Hardjosubroto, 1994). Waktu perhitungan dan populasi yang berbeda, akan menyebabkan perbedaan nilai heritabilitas yang diperoleh karena terjadi perubahan komposisi ternak dan ragam genetik yang terdapat di dalam populasi. Manajemen pengelolaan juga mempengaruhi nilai heritabilitas. Prosedur pengelolaan dibakukan semaksimum mungkin dan membuat penyesuaian terhadap pengelolaan atau lingkungan yang tidak memungkinkan akan meningkatkan nilai heritabilitas (Warwick et al., 1990; Hardjosubroto, 1994).

Hasil estimasi nilai heritabilitas berat umur satu tahun lebih tinggi dibandingkan dengan hasil penelitian Sukmasari (2001) yaitu 0,38 $\pm 0,02$ maupun Gunawan dan Jakaria (2011) sebesar $0,43 \pm 0,10$ namun berada pada kisaran 0,30 sampai 0,55 (Hardjosubroto, 1994). Nilai heritabilitas yang diperoleh dalam penelitian ini tergolong tinggi. Bila seekor ternak menunjukkan keunggulan pada sifat yang mempunyai pewarisan tinggi maka dapat diharapkan bahwa anaknya pun kelak akan mempunyai keunggulan dalam hal sifat tersebut (Hardjosubroto, 1994; Lasley, 1978). Nilai heritabilitas yang tinggi merupakan petunjuk bahwa sifat tersebut dapat digunakan sebagai salah satu kriteria seleksi pada sapi Bali.

Salah baku berat satu tahun yang diperoleh lebih rendah dari nilai heritabilitasnya hal ini menunjukkan tingginya keterandalan nilai heritabilitas tersebut. Heritabilitas bukan suatu konstanta tetapi hanya berlaku pada populasi tertentu, waktu tertentu dan metode perhitungan tertentu (Edey, 1983; Pirchner, 1969; Falconer dan Mackay, 1996). Beberapa lingkungan dapat menyebabkan ekspresi perbedaan genetik yang lebih besar dan karena itu memperbesar keragaman genetik dan heritabilitas (Warwick et al., 1990). Waktu perhitungan dan populasi yang berbeda, akan menyebabkan perbedaan nilai heritabilitas yang diperoleh karena terjadi perubahan komposisi ternak dan ragam genetik yang terdapat di dalam populasi (Hardjosubroto, 1994). Manajemen pengelolaan juga mempengaruhi nilai heritabilitas. Prosedur pengelolaan dibakukan semaksimum mungkin dan membuat penyesuaian terhadap pengelolaan atau lingkungan yang tidak memungkinkan akan meningkatkan nilai heritabilitas (Warwick et al., 1990).

\section{Kesimpulan}

Nilai heritabilitas berat lahir, sapih, dan umur satu tahun sapi Bali di BPTU Sapi Bali tergolong tinggi sehingga dapat digunakan sebagai kriteria seleksi.

\section{Daftar Pustaka}

Becker, A. W. 1992. Manual of Procedures Quantitative Genetics. 4 th ed. Washington State University Pullman. WA 99163-0666, USA.

Dalton, D. C. 1980. An Introduction to Practical Animal Breeding. Granada. London, Toronto Sydney, New York.

Edey, T. N. 1983. Tropical Sheep and Goat Production. Australian Universities International Development Program (AUIDP), Canberra.

Falconer D. S. and T. F. C. Mackay. 1996. Intoduction to Quantitative Genetics. Fourth Edition. Logman Group Ltd, CM 202 JE, England.

Gunawan, A. and Jakaria. 2011. Genetic and nongenetic effect on birth, weaning and yearling weight in Bali cattle. Media Peternakan. Available at http://medpet.journal.pbb.ac.id/ DOI:10.5398/medpet:2011.34.2.93.

Accession date: March 21, 2013.

Gunawan, D. Pamungkas, dan L. Affandhy. 1998. Sapi Bali, Potensi, Produktivitas dan Nilai Ekonomi. Kanisius. Yogyakarta.

Hardjosubroto, W. 1994. Aplikasi Pemuliabiakan Ternak di Lapangan. Grasindo. Jakarta.

Jan, R. 2000. Penampilan sapi Bali di wilayah Proyek Pembibitan dan Pengembangan Sapi Bali di Daerah Tingkat I Bali. Tesis Pascasarjana. Universitas Gadjah Mada, Yogyakarta.

Lasley, J. F. 1978. Genetics of Livestock Improvement $3^{\text {rd }}$ ed., Prentice-Hall Inc., Eaglewood Cliff, New Jersey.

Pane, I. 1990. Pemuliabiakan Ternak Sapi. Cetakan kedua. PT Gramedia Pustaka Utama, Jakarta.

Pirchner, F. 1969. Population Genetics in Animal Breeding. W. H. Freeman and Company, San Francisco.

Sudrana, I. P. 1988. Performans produksi sapi Bali di wilayah Proyek Pembibitan dan Pengembangan Sapi Bali Timor Barat. Tesis. Pascasarjana. Universitas Gadjah Mada, Yogyakarta.

Sukmasari, A. H. 2001. Pendugaan nilai pemuliaan dan kecenderungan genetik (genetic trends) bobot badan sapi Bali di Proyek Pembibitan dan Pengembangan Sapi Bali (P3Bali) di Bali. Tesis. Program Pascasarjana. Insitut Pertanian Bogor. Bogor.

Taylor, R. E. 1984. Beef Production and The Beef Industry. Macmillan Publishing Company, New York. 
Warwick, E. J., J. M. Astuti, dan W. Hardjosubroto. 1990. Pemuliaan Ternak. Gadjah Mada University Press, Yogyakarta. 